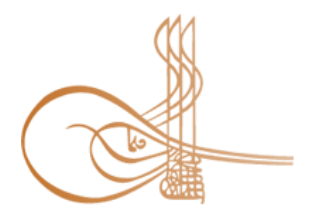

www.turkishstudies.net/social
Turkish Studies - Social Sciences

eISSN: 2667-5617

Research Article / Araștırma Makalesi

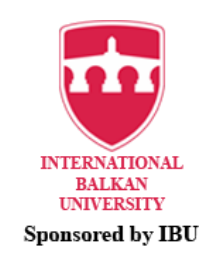

Sponsored by IBU

\title{
Mobbingin Taekwondo Hakemlerinin Karar Verme Düzeylerine Etkisi*
}

The Effect Of Mobbing Taekwondo Referee on Decision Making Levels

\author{
Yeşim Bayrakdaroğlu** - Kübra Eren ${ }^{* * *}$
}

\begin{abstract}
In this study, the decision making styles of the taekwondo referees exposed to mobbing and the levels of mobbing were examined based on some variables. The sample of the study consisted of 187 referees who worked in various provinces in Turkey and participated in the development seminars for referees and coaches organized by Turkey Taekwondo Federation in 2019-2020. The seminar was conducted on 19-27 December 2019 in Antalya, in 3 groups (turkiyetaekwondofed.gov.tr) In addition to the personal information form prepared by the researcher, the "Scale for Indoor Mobbing directed to Sports Referees", "Melbourne Decision Making Questionnaire I-II" were used in the study. The analysis of the data obtained in the research was examined by Statistical Package for the Social Sciences (SPSS). Frequency, percent, std. deviation, mean calculations, T-test and one-way variance analysis (ANOVA), Tukey test, and Pearson correlation analysis were used. Cronbach's Alpha coefficient was determined as 846 for decision-making scale and 883 for the mobbing scale. The study results revealed various levels of significance for variables were interpreted. In addition, it was determined that there were positive and significant relationships between the subdimension of decision making styles and mobbing $(\mathrm{r}=0.33, \mathrm{p}<0.01)$ and mobbing from the sports circle $(\mathrm{r}=0.22, \mathrm{p}, 0.01)$. Therefore, it can be said that mobbing perceived from the social circle did not have a significant effect on decision making styles of taekwondo referees. As a result, it can be said that the mobbing variable poses a significant risk to taekwondo referees' sub-dimension of decision making styles and said risk should be taken into consideration.
\end{abstract}

Structured Abstract: Aim: Mobbing is defined in different ways, such as all kinds of systematic maltreatment exposed to a person by his/her superiors, subordinates, and peers (Tutar, 2004:94), negative behaviors targeting a particular person (Baykal, 2005:25), cause someone to be dismissed from their jobs through systematic pressures with unethical approaches by reducing their performance and endurance. It is observed that athletes, especially with fatigue in sports competitions, exhibit behaviors such as violation of the rules of the match as the ambition to win increases. In this case, although they know the rules, the athletes may not behave sympathetically to the referee and do not respect or obey the decisions of the referee. In modern society, in determining our real values, the referees are the ones who should prevent negative

\footnotetext{
* Çalışmanın verileri 2019 yılında tamamlanmıştır.

** Dr. Öğr. Üyesi, Gümüşhane Üniversitesi, Beden Eğitimi ve Spor Yüksekokulu, Spor Yöneticiliği Bölümü

Asst. Prof. Dr., Gümüşhane University, High School of Physical Educaiton and Sport, Department of Sport Management ORCID 0000-0003-1460-4780

yesimsongun@hotmail.com

*** Öğrenci, Gümüşhane Üniversitesi, Beden Eğitimi ve Spor Yüksekokulu, Beden Eğitimi ve Spor Öğretmenliği Bölümü Student, Gümüşhane University, High School of Physical Educaiton and Sport, Physical Education and Sports Teaching Department

ORCID 0000-0001-5806-0725

kubraaerenn41@gmail.com

Cite as/Atıf: Bayrakdaroğlu, Y., \& Eren, K. (2020). Mobbingin taekwondo hakemlerinin karar verme düzeylerine etkisi. Turkish Studies-Social, 15(5), 2401-2412. https://dx.doi.org/10.47356/TurkishStudies.44329

Received/Geliş: 18 June/Haziran 2020

Accepted/Kabul: 20 August/Ağustos 2020

Copyright (C) INTAC LTD, Turkey

Checked by plagiarism software

Published/Yayın: 30 August/Ağustos 2020

CC BY-NC 4.0
} 
behaviors in matches but with a wrongly made decision, they can sometimes involuntarily become the person who causes the incidents to increase. In order for the indoor sports' referees to perform their duties, they should feel well both physically and mentally. The refereeing, which is considered as an especially risky profession (Hançerlioğlu, 1992), requires various qualifications such as communication, game knowledge, and evaluation skills. In addition to these features, referees are to know what the mobbing behaviors are, which can negatively affect their profession, and how to cope with them. In this context, considering that referees could be exposed to mobbing behaviors, it was aimed to prepare a mobbing scale regarding the indoor sports' referees who affect the masses and set the agenda with the decision they made during the competitions, thus determining the mobbing perception levels of the indoor sports' referees (Hacicaferoğlu, 2014). In this study, the decision making styles of the taekwondo referees exposed to mobbing and the levels of mobbing were examined based on some variables.

Material and Method: In this study, the decision making styles of the taekwondo referees exposed to mobbing and the levels of mobbing were examined based on some variables. The sample of the study consisted of 187 referees who worked in various provinces in Turkey and participated in the development seminars for referees and coaches organized by Turkey Taekwondo Federation in 2019-2020. The seminar was conducted on 19-27 December 2019 in Antalya, in 3 groups (turkiyetaekwondofed.gov.tr) In addition to the personal information form prepared by the researcher, the "Scale for Indoor Mobbing directed to Sports Referees", "Melbourne Decision Making Questionnaire I-II" were used in the study. The analysis of the data obtained in the research was examined by Statistical Package for the Social Sciences (SPSS). Frequency, percent, std. deviation, mean calculations, T-test and one-way variance analysis (ANOVA), Tukey test, and Pearson correlation analysis were used. Cronbach's Alpha coefficient was determined as 846 for decisionmaking scale and 883 for the mobbing scale. The frequency values obtained in the study are given in the table below.

Findings: The decision-making styles of taekwondo referees exposed to mobbing did not differ significantly in terms of the sub-dimension of self-esteem $\left(\mathrm{t}_{185}=0.14, \mathrm{p}>0.05\right)$ and the sub-dimension of decision-making styles $\left(\mathrm{t}_{185}=0.14, \mathrm{p}>0.05\right)$ in terms of gender. It was also determined that the mobbing levels of taekwondo referees did not differ significantly in terms of gender $\left(t_{185}=0.33, p>0.05\right)$. It was determined that the decision making levels of the taekwondo referees exposed to mobbing did not differ significantly in the dimension of self-esteem $\left(\mathrm{F}_{183}=1.10, \mathrm{p}>0.05\right)$ and in the sub-dimension of the decision-making styles $\left(\mathrm{F}_{183}=0.99, \mathrm{p}>0.05\right)$ according to the refereeing level. It can be said that the level of exposure to mobbing $\left(\mathrm{F}_{183}=2.55, \mathrm{p}>0.05\right)$ for the taekwondo referees did not differ significantly according to the refereeing level variable and the refereeing level did not have a significant effect on exposure to mobbing. Although the decision making levels of the taekwondo referees exposed to mobbing did not differ significantly according to their marital status in the dimension of self-esteem $\left(\mathrm{t}_{185}=1.75, \mathrm{p}>0.05\right)$, there was a significant difference in the sub-dimension of the decision-making styles $\left(\mathrm{t}_{185}=5.45, \mathrm{p}<0.05\right)$ according to the marital status variable. In addition, it was determined that the mobbing exposure levels of the taekwondo referees $\left(t_{185}=\right.$ $0.33, \mathrm{p}>0.05)$ did not differ significantly according to their marital status. It was determined that there was no significant difference according to education level in self-esteem subdimension $(F 183=, 87, p>, 05)$ of the decision making levels in taekwondo referees who were exposed to mobbing, on the other hand there was a significant difference in the decision-making style subdimension $(\mathrm{F} 183=4,79, \mathrm{p}<, 05)$ according to education level.Tukey test was used to determine the source of difference between mean values.It was determined that the mobbing levels $(\mathrm{F} 183=, 50, \mathrm{p}>, 05)$ of taekwondo referees did not show a significant difference according to education level.There was also no significant relation found between $(r=, 09, p>, 05)$ self-esteem and mobbing subdimensions in the decision-making styles. On the other hand it was determined that there were positive way and significant relations between $(r=, 33, p<, 01)$ the decision-making styles subdimension of the decision making levels and mobbing.After examining the relations between scales, in the analysis of predictor relations; analysis continued only with the variables which had significant correlations in between.In this context, self-esteem variable was not included in Regression analysis as it did not yield significant relation. The decision-making styles subdimension was analyzed only with mobbing as it had a significant relation with it and prediction coefficients between the decision-making styles subdimension and mobbing were assessed.

Conclusion: As a result, several significance levels were determined and interpreted in terms of some variables. In addition, it was determined that there were positive way and significant relations between $(\mathrm{r}=, 33, \mathrm{p}<, 01)$ the decision-making styles subdimension and mobbing. In other words, it can be suggested that a negativity that may occur in terms of mentioned variables may have a direct effect on the decision- 
making styles. In conclusion it can be suggested that mobbing variable may pose a risk on the decisionmaking styles subdimension in taekwondo referees and this risk is recommended to consider.

Keywords: Sports Management, Mobbing, Taekwondo, Decision Making, Referee

Öz: Bu çalışmada mobbinge maruz kalan taekwondo hakemlerinin karar verme stilleri ve mobbing düzeyleri bazı değişkenler baz alınarak incelenmişir. Araştırmanın örneklemini Türkiye Taekwondo Federasyonu tarafından düzenlenen 2019-2020 yılı hakem ve antrenör gelişim seminerine katılan ve Türkiye'nin çeşitli illerinde görev yapan 187 hakem oluşturmaktır. Seminer 19-27 Aralık 2019 tarihleri arasında 3 grup halinde Antalya'da yapılmıştır (turkiyetaekwondofed.gov.tr). Çalışmada araştırmacı tarafindan hazırlanan kişisel bilgi formunun yanında "Salon Sporları Hakemlerine Yönelik Mobbing Ölçeği”, "Melbourne Karar Verme Ölçeği I-II” ve Çakır (2019) tarafından hazırlanmış anket kullanılmıştır. Araştırmada elde edilen verilerin analizi istatistik paket programı yardımıyla test edilmiştir. Çalışmada frekans, yüzde, std. sapma, ortalama hesaplamaları, T-testi ve tek yönlü varyans analizi (ANOVA), tukey testi ve pearson korelasyon analizleri kullanılmıştır. Cronbach's Alpha katsayısı karar verme ölçeği için, 846, mobbing ölçeği için ise, 883 olarak tespit edilmiştir. Çalışmada frekans, yüzde, std. sapma, ortalama hesaplamaları, T-testi ve tek yönlü varyans analizi (ANOVA), tukey testi ve pearson korelasyon analizleri kullanılmıştır. Çalışma sonucunda değişkenler açısından çeşitli anlamlılık düzeyleri tespit edilmiş ve yorumlanmıştır. Ayrıca karar verme stilleri alt boyutu ile mobbing arasında $(r=, 33, p<, 01)$ pozitif yönde ve anlamlı ilişkiler olduğu belirlenmiştir. Yani söz konusu değişkenler açısından ortaya çıkacak olan bir olumsuzluğun karar verme stilleri üzerinde doğrudan bir etki oluşturabileceği söylenebilir. Sonuç olarak mobbing değişkeninin taekwondo hakemlerinde karar verme stilleri alt boyutu üzerinde önemli bir risk oluşturduğu ve bu riskin dikkate alınmasında yarar olduğu söylenebilir.

Anahtar Kelimeler: Spor Yönetimi, Mobbing, Taekwondo, Karar Verme, Hakem

\section{Giriș}

"Mob" kelimesinden türetilen mobbing İngilizce kökenli bir kelimdir. Çete, gürültücü kalabalık, gruplar halinde saldırmak gibi anlamların yanında, psikolojik şiddet ve rahatsız etme anlamlarını da içermektedir (Tınaz, 2006:13).

Mobbing; çalışanlara çevresinden sistematik bir biçimde uygulanan her türlü kaba yöntem (Tutar, 2004:94); belirli bir kişiyi hedef alan olumsuz davranışlar (Baykal, 2005:25); kişiye belirli aralıklarla baskı uygulayarak, ahlak dışı tavırlarla o kişilerin performanslarını etkileyip işten çıkarılmalarını neden olmak gibi değişik biçimlerde adlandırılmaktadır (Çobanoğlu, 2005:14). Leymann mobbing tavırlarını ifade ederken bu tavırların bir çeşit işyeri sorunu olduğunun üzerinde durmuştur. Bu sorun bir veya daha fazla bireyin sadece bir bireye sistemli bir şekilde gösterdikleri ahlak dıșı üslup ve düşmanca tavırları içermektedir (Leymann, 1996:167). Bütün bu tanımlamalarda hareketle, mobbing davranışlarının kişiyi yıldırma amaçlı olup planlı bir şekilde uzun süre devam eden etkinlikler olduğu söylenebilir.

Günlük yaşantımız içinde çeşitli durumlar ve olaylar karşısında sürekli olarak insanlar hemen hemen her alanda karar vermektedirler. Spor bu alanlarda yer almaktadır. Karar verme işlemi arasında beklenilen bütün yöntemlerin, özelliklerinin ve beklenilen sonuçlarının aynı zamanda değerlendirilmesi tüm zamanlarda mümkün olmayabilir. Bu sebeple bu süreçler belirli bir sisteme göre düzenlenir. İșlemlerin dizilimi karar vermede kalıcı etkiler bırakabilir (Newell vd., 2004:120). Bireyin karar vermesinde, bireysel farklılıklar önceliklidir. Bu farklılıklar çerçevesinde birey karar verme stilini belirleyebilmektedir. Bu sirada karar verme stili, bireyin karar verme durumlarındaki tepkisini ve eylemlerde içinde bulunduğu durum (Phillips vd., 1984:496) olarak tanımlanmaktadır.

Hakemlik de, kısa bir zamanda karar verme becerisini içeren meslek gruplarından biri olarak bilinmektedir ve hakemler belirlenmiş branşların müsabaka kuralları ile uygulama alanında özel bir bilgi birikimine sahip kişilerdir (Ekblom, 1994:102). Hakemler oyun alanında rekabet 
halinde olan sporcularla birlikte müsabakaya direkt olarak müdahale edebilirler. Müsabakaların sağlıklı bir şekilde gerçekleşmesini sağlamak ve müsabakanın sonuçlandırılması hakemlerin görevleri arasındadır. Adil oyun anlayışı çerçevesinde oyun kurallarını uygulamak hakemin temel amacını oluşturmalıdır (Cengiz ve Pulur, 2004:29). Hakemin karar vermesi olumsuz bir hareketin meydana geldiği anda ya da muhtemel olan en kısa zamanda gerçekleşmelidir. Hakemin öncelikle hareketi anlaması ve değerlendirmesi gerekmektedir. Hakemler kendilerine güvenmeli, zira başarılı bir hakem olmak için güven duygusu önem taşımaktadır (Weinberg \& Richardson, 1990). Çünkü müsabaka içerisinde yorulan sporcular maçın lehlerine sonuçlanması amaçlı hırslanırlar. $\mathrm{Bu}$ durumlarda muhtemel kural ihlalleri görülür. Bu tarz durumlarda sporcular genellikle hakemlere karşı anlayışlı davranamazlar (Vautrot, 2003). Ancak kararlı bir hakem bu durumları tölere edebilir.

Taekwondo da disiplin ile kazanılan duygusal ve sosyal gelişimler hedeflenir. Yani, sporcu coşku oluşturan duygularını kontrol altına alırken ortaya çıkan rekabetle birlikte birçok sosyal becerisini geliştirebilir. Kişi kuralları ve taktikleri anlayıp uygularken düşünme yeteneği de kazanır. Taekwondo kişilerin düşünme kapasitelerinin ve olaylara bakış açılarının üzerinde olumlu etkiler oluşturabilir (Heller vd., 1998:245). Salon sporları içinde geçen taekwondo hakemler açısından da çok dikkatli karar verilmesi gereken bir branştır. Hakemlerinin başarılı bir şekilde müsabakayı sonuçlandırabilmeleri için fiziksel ve ruhsal olarak hazır olmaları gerekmektedir. Özellikle zor bir meslek olan hakemlik için (Hançerlioğlu, 1992); iletişim, oyun bilgisi ve sonuca yönelik değerlendirme yetenekleri önemli unsurlardır. Mobbing davranışları hakemlerin karalarını olumsuz yönde etkileyebilir. Bu tarz oluşumlara yönelik, hakemler hazırlıklı olup mobbingle nasıl başa çıkabileceğini bilmelilerdir (Hacıcaferoğlu, 2014:48). Bu çalışmada mobbinge maruz kalan taekwondo hakemlerinin karar verme stilleri bazı değişkenler baz alınarak incelenmiş ve hakemlere uygulanan mobbingin karar verme düzeyleri üzerine etkisinin olup olmadığı araştırılmıştır.

\section{Materyal Metod}

Çalışmada taekwondo hakemlerinin karar verme ve mobbing düzeyleri çeşitli değişkenler göz önünde bulundurularak incelenmiştir. Araştırma genel ve ilişkisel yöntem tarama modeline göre yapılmıştır. Tarama modelleri; geçmişte ya da günümüzde var olan bir olayı, var olduğu haliyle betimlemeyi hedefleyen araştırma yaklaşımıdır (Karasar, 2012). Katılımcıların yanıtlarda herhangi bir değişiklik yapılmadan veriler toplanmış var olan durum hakkında bireylerin görüşleri alınmaya çalışılmıştır. Araştırmanın evrenini, Türkiye Taekwondo Federasyonuna bağlı faal olarak görev yapan 262 kadın, 417 erkek olmak üzere toplam 679 hakem oluşturmuştur (turkiyetaekwondofed., 2019). Araştırmanın örneklemini ise Türkiye'nin farklı bölgelerinde görev alan, Türkiye Taekwondo Federasyonu tarafindan düzenlenen 2019-2020 y1lı antrenör ve hakem eğitim seminerine katılan 230 hakem oluşturmaktır. Seminer 19-27 Aralık 2019 tarihleri arasında 3 grup halinde Antalya'da yapılmıştır (turkiyetaekwondofed.gov.tr). Çalışmaya katılan hakemlere anket soruları içerisinde yer alan 'Bir sezon veya altı ay içinde çalışma ortamında herhangi bir yıldırma (mobbing) davranışlarına maruz kaldınız mı?’ sorusu yöneltilmiştir. 187 hakem bu soruya evet yanıtı vermiştir ve çalışma bu 187 hakem üzerinden yürütülmüştür. Çalışma kapsamında hazırlanan kişisel bilgi formunun yanında "Salon Sporları Hakemlerine Yönelik Mobbing Ölçeği”, "Melbourne Karar Verme Ölçeği I-II" kullanılmıştır.

Yıldırma (mobbing) düzeylerini belirlemek için, "Salon Sporları Hakemlerine Yönelik Mobbing Ölçeği” kullanılmıştır (Hacıcaferoğlu, 2014). Hacıcaferoğlu (2014) tarafından geliştirilen ve geçerlik güvenirlik yapılan "Salon Sporları Hakemlerine Yönelik Mobbing Ölçeği” beşli likert tipinde 31 maddeden oluşmaktadır. Ölçeğin orjinalinde maddeler hakemlere uygulandıktan sonra faktör analizi gerçekleştirilmiştir. Faktör analizi işleminden elde edilen verilere göre ölçek; 14 madde ile tek bileşenli bir yapıya sahip olduğu anlaşılmıştır. Ölçekte yer alan maddelerin açıkladığ 1 toplam varyansın 43.721 , faktör yüklerinin ise 0.48 ile 0.76 arasında olduğu tespit edilmiştir. Ölçeğin cronbach's alpha iç tutarlılık katsayısı ise 0.82 olarak hesaplanmıştır. 
Çalışmada kullanılan diğer bir ölçek iki kısımdan oluşan "Melbourne Karar Verme Ölçeği”dir. Mann ve Diğ. (1998)'in geliştirmiş olduğu Melbourne Karar Verme Ölçeğini, (Melbourne Decision Making Questionary) Deniz (2004), uyarlamasını yaparak Türkçe'ye adapte etmiştir. Melbourne Karar Verme Ölçeği I-II (MKVÖ)'nin geçerlik ve güvenirlik çalışmaları 20022003 yılları arasında Selçuk Üniversitesi Teknik Eğitim Fakültesi Bilgisayar Sistemleri Öğretmenliği ve Otomotiv Öğretmenliği öğrencilerine yapılmış ve 154 öğrenciden bilgi alınmıştır (Deniz, 2004). Bu ölçek iki kısımdan oluşmaktadır. Ölçeğin Birinci Kısmı: Karar vermede özsaygıyı (kendine güven) ölçmeyi hedeflemektedir. Üç madde düz, üç madde aksi yönde puanlanıp altı maddeden meydana gelmektedir. "Doğru" cevap 2, "Bazen Doğru" cevab1 1, "Doğru Değil" cevabı 0 puan olarak yapılmaktadır. Sonuçlardan alınabilecek en yüksek puan 12'dir. Puanların fazla olması karar vermede özsaygının yüksekliğinin belirtisidir. Ölçeğin İkinci Kısmı; karar verme stillerini ölçmektedir. Dikkatli (6 soru ), Kaçıngan (6 soru ), Erteleyici (5 soru) ve Panik (5 soru) karar verme stilleri olmak üzere dört alt faktörlü 22 sorudan oluşmaktadır (Deniz, 2004).

Araştırmada elde edilen verilerin analizi ilgili istatistik programı kullanılarak test edilmiştir. Çalışmada frekans, yüzde, std. sapma, ortalama hesaplamaları, T-testi ve tek yönlü varyans analizi (ANOVA), tukey testi ve pearson korelasyon analizleri kullanılmıştır. Cronbach's Alpha katsayısı karar verme ölçeği için, 846, mobbing ölçeği için ise, 883 olarak tespit edilmiştir.

\section{Bulgular}

Taekwondo hakemlerinin maruz kaldıkları mobbingin karar verme düzeyleri üzerindeki etkisi ve mobbinge maruz kalma düzeyleri çeşitli değişkenler açısından analiz edilmiş ve ulaşılan sonuçlar aşağıda sunulmuştur.

Tablo 1: Araştırmaya Katılan Taekwondo Hakemlerinin Demografik Bilgileri

\begin{tabular}{cccc} 
Değişken & Alt Değişken & F & \% \\
\hline \multirow{2}{*}{ Cinsiyet } & Kadın & 92 & 49,2 \\
& Erkek & 95 & 50,8 \\
& Aday & 84 & 44,9 \\
\multirow{3}{*}{ Hakemlik seviyesi } & Bölge & 64 & 34,2 \\
& Ulusal & 27 & 14,4 \\
& Uluslararası & 12 & 6,4 \\
\multirow{3}{*}{ Medeni durum } & Evli & 74 & 39,6 \\
& Bekâr & 113 & 60,4 \\
\multirow{2}{*}{ Eğgitim durumu } & Lise & 58 & 31,0 \\
& Yükseköğrenim & 100 & 53,5 \\
& Yüksek lisans & 29 & 15,5 \\
\hline
\end{tabular}

Araştırmaya katılan taekwondo hakemlerinin \%49,2 si kadınlar \%50,8 i erkeklerden oluşmaktadır. \%44,9 u aday hakem, \% 34,2 si bölgesel hakem, \%14,4 ulusal hakem, \%6,4'ü ise uluslararası hakem seviyesindedir. Hakemlerin \%39,6's1 evli \%60,4'ü ise bekârdır. Eğitim durumlarına bakıldığında ise hakemlerin \%53,5 'i yükseköğrenim, \%31,0'1 lise, \%15,5'i yüksek lisans mezunu olduklarını ifade etmişlerdir. 
Tablo 2: Cinsiyete Göre Hakemlerin Karar Verme Stillerinin ve Mobbinge Maruz Kalma

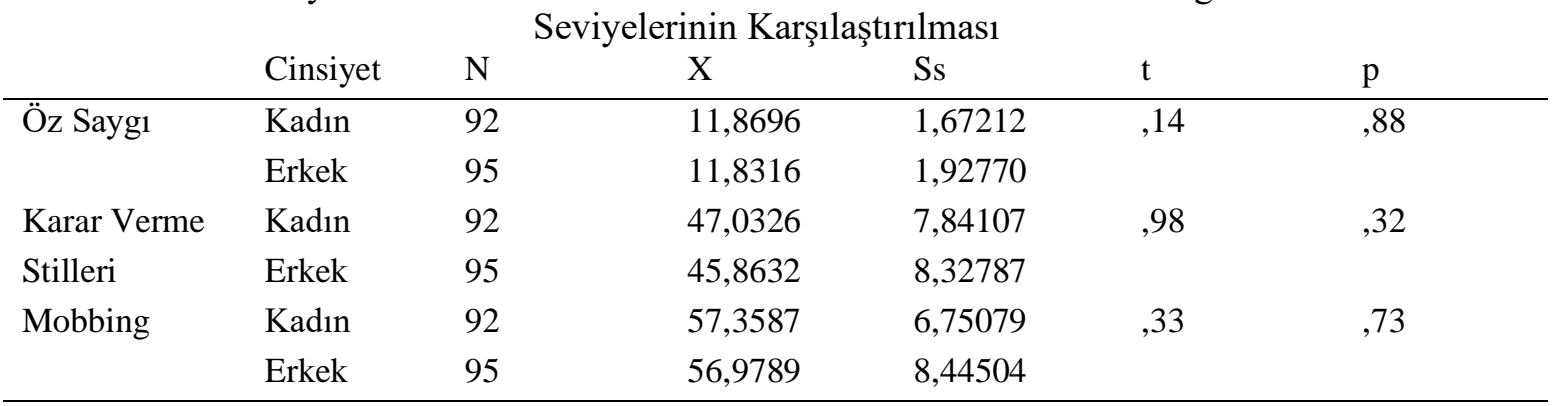

Tablo incelendiğinde mobbinge maruz kalan taekwondo hakemlerinin karar verme stillerinin öz sayg1 alt boyutunda $\left(\mathrm{t}_{185}=, 14, \mathrm{p}>, 05\right)$ ve karar verme sitilleri alt boyutunda $\left(\mathrm{t}_{185}=, 14\right.$, $\mathrm{p}>, 05)$ ayrıca mobbing açısından $\left(\mathrm{t}_{185}=, 33, \mathrm{p}>, 05\right)$ cinsiyet açısından anlamlı düzeyde farklılaşma göstermediği tespit edilmiştir.

Tablo 3: Hakemlik Seviyelerine Göre Hakemlerin Karar Verme Stillerinin ve Mobbinge Maruz

Kalma Seviyelerinin Karşılaştırılması

\begin{tabular}{lllllll}
\hline & Hakemlik seviyesi & $\mathrm{N}$ & $\mathrm{X}$ & $\mathrm{Ss}$ & $\mathrm{F}$ & $\mathrm{p}$ \\
\hline Öz Sayg1 & Aday & 84 & 11,9762 & 1,52865 & 1,10 &, 34 \\
& Bölge & 64 & 11,9688 & 1,99180 & & \\
& Ulusal & 27 & 11,4074 & 2,15298 & & \\
& Uluslararas1 & 12 & 11,3333 & 1,61433 & &, 39 \\
Karar & Aday & 84 & 46,8333 & 7,12172 &, 99 & \\
Verme & Bölge & 64 & 46,5000 & 8,18632 & & \\
Stilleri & Ulusal & 27 & 46,7778 & 8,91556 & & \\
& Uluslararas1 & 12 & 42,5833 & 11,61862 & & \\
Mobbing & Aday & 84 & 11,9762 & 1,52865 & 2,55 & \\
& Bölge & 64 & 11,9688 & 1,99180 & & \\
& Ulusal & 27 & 11,4074 & 2,15298 & & \\
& Uluslararas & 12 & 11,3333 & 1,61433 & & \\
& & & & & &
\end{tabular}

Tablo 3 incelendiğinde mobbinge maruz kalan taekwondo hakemlerinin karar verme düzeylerinin öz saygı boyutunda $\left(\mathrm{F}_{183}=1,10, \mathrm{p}>, 05\right)$ ve karar verme stilleri alt boyutunda $\left(\mathrm{F}_{183}=\right.$ ,99, p>,05) hakemlik seviyesi değişkenine göre anlamlı düzeyde farklılaşma göstermediği belirlenmiştir. Mobbinge maruz kalan taekwondo hakemlerinin Mobbinge maruz kalma düzeylerinin $\left(\mathrm{F}_{183}=2,55, \mathrm{p}>, 05\right)$ hakemlik seviyesi değişkenine göre de anlamlı düzeyde farklılaşma göstermediği ve hakemlik seviyesinin mobbinge maruz kalan hakemlerde mobbinge maruz kalma üzerinde belirgin bir etkiye sahip olmadığı söylenebilir. 
Tablo 4: Medeni durumlarına Göre Hakemlerin Karar Verme Stillerinin ve Mobbinge Maruz Kalma Seviyelerinin Karşılaştırılması

\begin{tabular}{lcccccc} 
& Medeni durum & $\mathrm{N}$ & $\mathrm{X}$ & $\mathrm{Ss}$ & $\mathrm{T}$ & $\mathrm{P}$ \\
\hline Öz Sayg1 & Evli & 74 & 11,6351 & 1,93436 & \multirow{2}{*}{, 75} &, 18 \\
& Bekâr & 113 & 11,9912 & 1,70344 & & \\
Karar Verme Sitilleri & Evli & 74 & 48,1216 & 9,18449 & $\mathbf{5 , 4 5}$ &, $\mathbf{0 2}$ \\
& Bekâr & 113 & 45,3363 & 7,11715 & & \\
Mobing & Evli & 92 & 57,3587 & 6,75079 & \multirow{2}{*}{, 33} &, 73 \\
& Bekâr & 95 & 56,9789 & 8,44504 & & \\
\hline
\end{tabular}

Tablo incelendiğinde mobbinge maruz kalan taekwondo hakemlerinin karar verme düzeylerinin öz saygı boyutunda $\left(\mathrm{t}_{185}=1,75, \mathrm{p}>, 05\right)$ medeni duruma göre anlamlı farklılaşma olmadığ1 buna karşın karar verme stilleri alt boyutunda $\left(\mathrm{t}_{185}=5,45, \mathrm{p}<, 05\right)$ medeni durum değişkenine göre anlamlı farklılaşma olduğu görülmüştür. Bunun yanında mobbinge maruz kalan taekwando hakemlerinin mobbing maruz kalma düzeylerinin $\left(\mathrm{t}_{185}=, 33, \mathrm{p}>, 05\right)$ medeni duruma göre anlamlı fark göstermediği belirlenmiştir.

Tablo 5: Eğitim Düzeylerine Göre Hakemlerin Karar Verme Stillerinin ve Mobbinge Maruz Kalma Seviyelerinin Karşılaştırılması

\begin{tabular}{cllllll} 
& Eğitim düzeyi & $\mathrm{N}$ & $\mathrm{X}$ & $\mathrm{Ss}$ & $\mathrm{F}$ & $\mathrm{P}$ \\
\hline \multirow{3}{*}{ Öz Sayg1 } & Lise & 58 & 12,0345 & 1,97320 &, 85 &, 44 \\
& Yükseköğrenim & 100 & 11,8800 & 1,57172 & & \\
& Yüksek lisans & 29 & 11,3914 & 2,11343 & & \\
Karar & Lise & 58 & 46,7586 & 6,89600 & 4,81 &, 00 \\
Verme & Yükseköğrenim & 100 & 46,6600 & 7,77359 & & \\
Sitilleri & Yüksek lisans & 29 & 47,4125 & 9,72564 & & \\
& Lise & 58 & 56,5000 & 7,74427 & \multirow{2}{*}{, 51} &, 69 \\
\multirow{2}{*}{ Mobbing } & Yükseköğrenim & 100 & 57,5000 & 7,96647 & & \\
& Yüksek lisans & 29 & 57,6918 & 6,31257 & & \\
\hline
\end{tabular}

Tablo incelendiğinde mobbinge maruz kalan taekwondo hakemlerinin karar verme düzeylerinin öz saygı boyutunda $\left(\mathrm{F}_{183}=, 85, \mathrm{p}>, 05\right)$ eğitim düzeyine göre anlamlı farklılaşma göstermediği tespit edilmiştir. Buna karşın karar verme stilleri alt boyutunda $\left(F_{183}=4,81, p<, 05\right)$ anlamlı bir fark tespit edilmiştir. Ortalamalar arasındaki farkın neden kaynaklandığını tespit etmek için Tukey testi uygulanmıştır. Mobbinge maruz kalan taekwondo hakemlerinin mobbinge maruz kalma düzeylerinin $\left(\mathrm{F}_{183}=, 51, \mathrm{p}>, 05\right)$ eğitim seviyelerine göre anlamlı farklılık göstermediği görülmektedir.

Tablo 6: Korelasyon Analizi Sonucu

\begin{tabular}{lll} 
& Öz Sayg 1 & Karar Verme Sitilleri \\
\hline Mobbing &, 095 &, $33^{* *}$
\end{tabular}

Tablo incelendiğinde karar verme stillerinin öz saygı alt boyutu ile mobbing arasındaki $(r=, 09, \mathrm{p}>, 05)$ ilişkilerin anlamlı olmadığı belirlenmiştir.

Buna karşın karar verme düzeylerinin karar verme stilleri alt faktörü ile mobbing $(r=, 33$, $\mathrm{p}<, 01)$ arasında pozitif ve anlamlı ilişki görülmüştür. 
Ölçekler arasındaki ilişkiler incelendikten sonra yordayıcı ilişsilerin analizinde ise yalnızca aralarında anlamlı korelasyon çıkan değişkenler ile analize devam edilmiştir. Bu kapsamda öz saygı değişkeni anlamlı ilişkiler vermediği için Regresyon analizine dahil edilmemiştir. Karar verme stilleri alt boyutu ise yalnızca anlamlı ilişkiye sahip olduğu mobbing ile birlikte analiz edilmiş ve aralarındaki yordama katsayıları hesaplanmıştır.

Regresyon analizinde öncelikle analizin ön koşulu olan kriterler incelenmiştir.

Tablo 7: Regresyon Analiz Tablosu

\begin{tabular}{llllll} 
& B & Std. hata & $\beta$ & $\mathrm{t}$ & $\mathrm{p}$ \\
\hline Mobbing &, 303 &, 081 &, 287 & 3,735 &, 000
\end{tabular}

$\mathrm{R}=, 34, \mathrm{R}^{2}=11, \mathrm{~F}=12,08, \mathrm{p}<, 00$

\section{Tartışma ve Sonuç}

Taekwondo hakemlerinin maruz kaldıkları mobbingin karar verme düzeyleri üzerindeki etkisi sonucu elde edilen veriler aşağıda değerlendirilmiştir.

Araştırma sonucunda mobbinge maruz kalan taekwondo hakemlerinin karar verme düzeylerinin öz saygı boyutunda ve karar verme stilleri alt boyutunda cinsiyetlerine göre anlamlı düzeyde farklılaşma göstermediği belirleniştir. Cinsiyetin mobbinge maruz kalan hakemlerde karar verme stilleri ve mobbing düzeyi üzerinde etkili bir unsur olmadığg söylenebilir. İncelenen birçok çalışmada, araştırma sonuçları ile benzer şekilde, cinsiyet değişkenine göre karar vermede öz saygının farklılaşmadığı sonucuna ulaşmışıtır (Avşaroğlu, 2007; Çetin, 2009; Ulaş vd., 2015; Kaşık, 2009; Kelecek ve arkadaşları, 2015; Vural, 2013). Bunun yanında Ramanigopal (2008) ve Taşgit (2012) yaptıkları çalışmalarda erkeklerin öz saygı düzeylerinin kadınların öz saygı düzeylerinden daha yüksek olduğunu tespit etmişlerdir. Kıratlı (2015) tarafından tenis hakemleri ile ilgili yapılan çalışmada, öz saygılarının cinsiyet değişkenine göre değişiklik gösterdiği tespit edilmiştir. Erkek hakemlerin kadın hakemlere göre karar vermede öz saygı düzeyleri daha yüksek bulunmuştur. Bu sonuç çalışmadan elde edilen verilerle uyuşmamaktadır. Kick boks hakemlerine yönelik yapılan başka erkeklerin dikkatli karar verme düzeyleri kadınlara oranda daha yüksek olduğu belirtilmiştir (Deryahanoğlu, 2014). Certel ve arkadaşları (2013) ise yaptıkları araştırmada karar vermede kadınların öz saygı düzeylerini erkeklerin öz saygı düzeyinden farklı bulmuştur. Mobbinge yönelik yapılan çalışma sonuçları incelendiğinde; bağlı hakemlerin çalışma sürelerince karşılaştıkları yıldırma tavırları ile cinsiyet değişkeni arasında anlamlı bir fark bulunamamıştır (Çakır, 2019). Leyman (1996) erkek üstünlüğünün fazla olduğu iş yerlerinde bayan çalışanların, bayanların üstün olduğu iş yerlerinde ise tam tersi olarak erkek çalışanların mobbinge maruz kalma durumlarının daha yüksek olduğunu belirtmiştir.

Hakemlik seviyesi açısından incelendiğinde, hakemlik seviyesinin mobbinge maruz kalan hakemlerde karar verme düzeyleri ve mobbinge maruz kalma düzeyleri üzerinde belirgin bir etkiye sahip olmadığı söylenebilir. Kıratlı (2015) yaptığı çalışmada karar verme stilleri alt faktörlerinden kaçıngan karar verme stilinin tenis hakemlerinin hakemlik kategorisi değişkeni açısından farklılaştığını tespit etmiştir. $\mathrm{Bu}$ sonuç çalışmamızla farklılık göstermektedir. $\mathrm{Bu}$ değişken açısından diğer karar verme stilleri ile anlamlı bir farklılaşma görülmemiştir. Uzunoğlu (2008) Türk futbol hakemlerinin karar verme stillerine yönelik sonuçlarında kaçıngan karar verme puan ortalamaları hakem klasmanları açısından karşılaştırıldığında klasmanlar arasında anlamlı bir farklılık bulmuştur. Kick boks hakemlerine yönelik yapılan çalışmada da elde ettiğimiz verilerin aksine hakemlerinin klasmanlarına göre aday hakemlerin milli hakemlere nazaran karar vermede öz saygı düzeylerinin daha düşük olduğu belirlenmiştir (Deryahanoğlu, 2014).

Medeni durum değişkeni incelendiğinde mobbinge maruz kalan taekwondo hakemlerinin karar verme düzeylerinin öz saygı boyutunda ve mobbinge maruz kalma düzeyleri açısından 
anlamlı farklılaşma göstermediği belirlenmiştir. Fakat karar verme düzeylerinin karar verme stilleri alt boyutunda medeni durum değişkeni açısından anlamlı farklılıkların olduğu ve bu farkın kaynağı incelendiğinde evli kişilerin puanlarının ortalamasının bekarlara göre fazla olduğu tespit edilmiştir. Elde edilen bulgular medeni durumun mobbinge maruz kalan hakemlerde karar verme stilleri alt boyutu açısından belirgin bir etkiye sahip olduğu şeklinde değerlendirilebilir. Konuyla ilgili Açıcı (2019) yaptığı çalışmada ulusal ve uluslararası voleybol hakemlerinin karar vermede öz saygı (kendine güven) ve karar verme stilleri bu değişken bakımından istatistikî açıdan anlamlı fark tespit etmeyerek çalışmanın aksine bir sonuç ortaya koymuştur. Gacar (2011) beden eğitimi ve spor öğretmenlerine yönelik yaptığı çalışmada bekâr olanların kaçıngan yaklaşım düzeyinin evli olanlara oranla daha yüksek olduğunu tespit ederek çalışmayla benzer sonuç ortaya koymuştur. Gacar (2011) çalışmasında öz saygı alt boyutu puanları açısından da medeni durum değişkenine göre araştırmaya benzer şekilde anlamlı olmayan sonuç tespit etmiştir. $(\mathrm{p}<0.05)$. Deryahanoğlu (2014) kick boks hakemleri ile yaptı̆̆ çalışmada hakemlerin karar verme öz saygı düzeyi, kaçıngan karar verme ve mesleki yeterlilik düzeylerinde medeni durum açısından anlamlı farklılık olduğu sonucuna varmıştır $(\mathrm{p}<0,05)$. Bu sonuç karar verme stilleri alt boyutu açısından çalışmayı desteklemektedir. Mobbing ile ilgili yapılan araştırmalar incelendiğinde medeni durum değişkeninin yıldırma davranışları açından fark oluşturacak bir etkiye sahip olmadığı görülmüsstür (Yavuz, 2007).

Eğitim düzeyi değişkeni incelendiğinde mobbinge maruz kalan taekwondo hakemlerinin karar verme düzeylerinin öz saygı boyutunda eğitim düzeyine göre anlamlı değişim göstermediği fakat karar verme stilleri alt boyutunda anlamlı bir fark tespit edildiği görülmektedir. Eğitim seviyesindeki artışın hakemlerin karar verirken kendine güven aşamasında faydalı olacağ düşünülmektedir. Karar verme stilleri alt boyutunda yüksek lisans düzeyine sahip olanların karar verme puan ortalamalarının diğer eğitim düzeyinde olanlara göre anlamlı boyutta daha düşük olduğu belirlenmiştir. Belirlenen sonuçta yüksek lisans düzeyinde eğitim seviyesine sahip olan katılımcı sayısının diğer gruplara kıyasla oldukça düşük olması gösterilebilir. Diğer eğitim düzeyleri kıyaslandığında puan ortalamaları arasında bir farklılaşma gözlenmemiştir. Dolayısıyla elde edilen sonuçlar yüksek lisans düzeyinde eğitim seviyesine sahip olanlarda puan ortalamasının anlamlı düzeyde daha düşük olduğuna işaret emektedir ve bu sonuç eğitim seviyesinin mobbinge maruz kalan hakemlerde karar verme stilleri üzerinde etkili bir unsur olduğu şeklinde değerlendirilebilir. Mobbinge maruz kalan taekwondo hakemlerinin mobbinge maruz kalma düzeylerinin bu değişken açısından anlamlı farklılık ortaya koymadığı belirlenmiştir. Göral (2014) Futbol antrenörlerinin karar verme stratejilerini eğitim düzeyi değişkeni açısından incelediğinde herhangi anlamlı bir fark tespit edememiştir $(\mathrm{p}>0.05)$. Ulusal ve uluslararası voleybol hakemleri üzerinde yapılan çalışmada eğitim düzeyi değişkenine göre, karar verme öz saygıda (kendine güven) anlamlı ilişki görülmüştür $(p<0,05)$. Ayrıca karar verme stilleri açısından istatistiki olarak anlamlı bir bulgu görülememiştir $(\mathrm{p}>0,05)$. Eğitim düzeyi değişkeninde, karar vermede öz sayg1 açısından, lise mezunlarına göre lisansüstü eğitim alanların puanlarının anlamlı biçimde yüksek olduğu görülmüştür (Açıc1, 2019). Bu sonuç bizim çalışmamızın aksine bir sonuç ortaya koymuştur. Uzunoğlu (2008) ve Vural (2013) yaptıkları çalışmalarda eğitim düzeyi değişkeni açısından karar vermede öz saygılarının araştırmamıza paralel olarak bir farklılaşma tespit edilmemiştir. Izgar ve Yılmaz (2007) ise karar verme stillerinin alt boyutlarından kaçıngan ve panik karar verme stillerinin diğer boyutlara oranla farklılaştığı sonucuna ulaşmışlardır. Bu açıdan eğitim düzeyi yüksek olmayan okul yöneticilerinin kaçıngan ve panik karar verme stillerini sıklıkla uyguladıkları görülmüştür $(\mathrm{p}<0,05)$.

Mobbinge maruz kalan taekwondo hakemlerinde mobbing ile karar verme stilleri arasinda anlamlı ilişki var mıdır ve taekwondo hakemlerinde mobbing karar verme stillerinin anlamlı bir yordayıcısı mıdır? Mobing artınca karar verme sitilleri değişiyor mu? Sorularının cevabı aranmıştır. İlgili tablo incelendiğinde karar verme stillerinin öz saygı alt boyutu ile mobbing arasındaki $(\mathrm{r}=, 09$, p>,05) ilişkilerin anlamlı olmadığı belirlenmiştir. Dolayısıyla karar verme öz saygı alt boyutu 
açısından mobbing taekwondo hakemlerinde karar verme düzeylerini etkileyen bir değişken olarak görülmeyebilir. Mobingin karar verme de öz saygı boyutunda karar verme düzeyini etkileyen bir değişken olmadığ 1 görülmüştür. Buna karşın karar verme düzeylerinin karar verme stilleri alt boyutu ile mobbing arasında pozitif yönde ve anlamlı ilişki içinde olduğu belirlenmiştir. Bu bulgu söz konusu değişkenler açısından ortaya çıkacak olan bir olumsuzluğun karar verme stilleri üzerinde doğrudan bir etki yaratabileceği şeklinde değerlendirilebilir. Yani mobbingin karar verme stili alt faktörü üzerinde pozitif ve anlamlı bağ görülmüştür.

Regresyon analizinin sonucunda, mobbing karar verme stilleri alt boyutundaki varyansin \% 11'ini açıkladıkları görülmektedir. Yordayıcılık açısından bakıldığında mobbing değişkeninin karar verme stilleri alt boyutunu pozitif yönlü ve anlamlı olarak yordadığı görülmektedir. Elde edilen bulgular doğrultusunda mobbing değişkeninin taekwondo hakemlerinde karar verme stilleri alt boyutu üzerinde önemli bir risk oluşturduğu ve bu riskin dikkate alınmasında yarar olduğu söylenebilir.

\section{Kaynakça}

Açıcı, S. (2019). Ulusal ve Uluslararası Voleybol Hakemlerinin Karar Verme Stillerinin İncelenmesi. Yayımlanmış Yüksek Lisans Tezi.

Avşaroğlu, S. (2007). Üniversite Öğrencilerinin Karar Vermede Özsayg1, Karar Verme ve Stresle Başa Çıkma Stillerinin Benlik Saygısı ve Bazı Değişkenler Açısından İncelenmesi. Yayımlanmış Doktora Tezi.

Baykal, A. N. (2005). Yutucu Rekabet: Kanuni Devrindeki Mobbingden Günümüze. Sistem.

Certel Z, Aksoy D, Çalışkan E, Yerlisu Lapa T, Özçelik MA \& Çelik G.( 2013). Research On SelfEsteem İn Decision Making and Decision Making Styles in Taekwondo Athletes. Procedia Social and Behavioral Sciences, (93), 1971-1975.

Cengiz, R. \& Pulur, A. (2004). Futbol Hakemlerinin Şiddet Olaylarına Bakış Açıları Üzerine Bir Araştırma. Atatürk Üniversitesi Beden Eğitimi ve Spor Bilimleri Dergisi, (1), 27-33.

Çetin, MÇ. (2009). Beden Eğitimi ve Spor Yüksekokulu Öğrencilerinin Karar Verme Stilleri Sosyal Beceri Düzeyleri ve Stresle Başa Çıkma Biçimlerinin Bazı Değişkenler Açısından Karşılaştırmalı Olarak İncelenmesi. Yayımlanmış Doktora Tezi.

Çobanoğlu, Ş. (2005). Mobbing ve Başa Çıkma Yöntemleri. Timaş.

Deniz, ME. (2004). Üniversite Öğrencilerinin Karar Vermede Öz Sayg1, Karar Verme Stilleri ve Problem Çözme Yöntemleri Arasındaki İlişkinin İncelenmesi Üzerine Bir Araştırma. Eğitim Araştırmaları Dergisi, 4(15):25-35.

Deryahanoğlu, G. (2014). Kick Boks Hakemlerinin Karar Verme ve Atılganlık Düzeylerinin Algılanan Mesleki Yeterlilik Üzerine Etkisinin İncelenmesi. Yayımlanmış Yüksek Lisans Tezi.

Ekblom, B. (1994). Handbook of Sports Science and Football. Black well Scientific Publication.

Gacar, A. (2011). Türkiye 'deki Beden Eğitim ve Spor Öğretim Elemanlarının Karar Verme ve Atılganlık Düzeylerinin Bazı Değişkenler Açısından İncelenmesi. Yayımlanmış Doktora Tezi.

Göral, K. (2014). Futbol Antrenörlerinin Yeterlilikleri, Karar Verme Stratejileri ve Takım Performansları Arasındaki İlişsinin İncelenmesi. Yayımlanmış Doktora Tezi.

Hacıcaferoğlu, S. (2014). Salon Sporları Hakemlerine Yönelik Mobbing Ölçeğinin Geçerlik ve Güvenirliğinin Belirlenmesi. International Journal of Science Culture and Sport. 46-96. 
Hançerlioğlu, O. (1992). Türk Dili Sözlüğü. Remzi Kitabevi.

Heller, J., Peric, T., Dlouha, R., Kohlikov, A.E., Melichna, J. \& Novakva, H. (1998). Physiological Profiles of Male and FemaleTaekwondo (ITF) Black Belts. Journal of Sports Science, 16: 243-249.

Izgar, H. \& Yılmaz, E. (2007). Pio ve Yibo'nda Görev Yapan Okul Yöneticilerinin Karar Vermede Özsayg1 ve Karar Verme Stilleri Arasındaki İlişki. Selçuk Üniversitesi Sosyal Bilimler Enstitüsü Dergisi, 341-351.

Karasar N. (2012) Bilimsel Araştırma Yöntemi. 17.Baskı. Nobel Yayın Dağıtım.

Kaşık, Z.D. (2009). Ergenlerde Karar Verme Stilleri ve Algılanan Sosyal Destek Düzeylerinin Sosyal Yetkinlik Beklentisi ve Bazı Değişkenler Açısından İncelenmesi. Yayımlanmış Yüksek Lisans Tezi.

Kelecek, S., Altıntaş, A. \& Aşçı, F.H. (2015). Sporcuların Karar Verme Stillerinin Belirlenmesi. Celal Bayar Üniversitesi Beden Eğitimi ve Spor Bilimleri Dergisi, 8(1):21-27.

Kıratlı, E. s(2015). Tenis Hakemlerinin Karar Verme Stilleri ve Empatik Eğitim Düzeylerinin Karşılaştırılmalı Olarak Değerlendirilmesi. Yayımlanmış Doktora Tezi.

Leymann, H. (1996). The Content and Development of Mobbing at Work. EuropeanJournal of Work and Organizational Psychology, 5(2): 165-184.

Mann, L.; Harmani, R., ve Pover (1989). Adolescent Decision-Making: The Development of Competence. Journal Of Adolescence, 12, 265-278.

Newell, B.R., Rakow, T., Weston, N.J. \& Shanks, D. R. (2004). Search Strategies İn Decison Making: The Success of 'Success'. Journal of Behavioral Decision Making, 17: 117-137.

Payne, W.J., Eric, J., \& James, R.B. (1993). The Adaptive Decision Maker. Cambridge University Press.

Phillips, S. D., Pazienza, N. J., \& Ferrin, H. H. (1984). Decision-Making Styles and ProblemSolving Apprasial. Journal of Counseling Psychology, 31, 497-502.

Ramanigopal, C.S. (2008). Self-esteem and Decision Making of School Teachers. Journal of the Indian Academy of Applied Psychology, 34:145-150.

Taşgit, S. M. (2012). Üniversite Öğrencilerinin Benlik Saygısı ve Karar Verme Düzeylerinin İncelenmesi. Yayımlanmış Yüksek Lisans Tezi.

Tinaz, P. (2006). Isşyerinde Psikolojik Taciz. Çalışma ve Toplum

Tutar, H. (2004). Isşyerlerinde Psikolojik Şiddet. Platin.

Türkiye Taekwondo Federasyonu. https://www.turkiyetaekwondofed.gov.tr/haber.asp? ID=210. Erişim Tarihi: 06.12.2019.

Ulaş, A. H., Epçaçan, C. \& Koçak, B. (2015). Öğretmen Adaylarının Karar Vermede Özsayg1 Düzeyi ve Karar Verme Stillerinin İncelenmesi. Turkish Studies International Periodical for the Languages, Literature and History of Turkish or Turkic, 10(3):1031-1052.

Uzunoğlu, U. Ö. (2008). Türk Futbol Hakemlerinin Karar Verme Stillerinin Klasmanlarına ve Bazı Değişkenlerine Göre İncelenmesi. Yayımlanmış Yüksek Lisans Tezi.

Weinberg, R. S. \& Richardson, P. A. (1990). Psychology of Officiating. Human Kinetics.

Vautrot, M. (2003). Referee is ThePart of The Game. <www.fifa.com-articles > Erişim tarihi:28.05.2020 
Vural, M. (2013). Spor Genel Müdürlüğü Merkez ve Taşra Teşkilatında Görev Yapan Spor Yöneticilerinin Düşünme ve Karar Verme Stillerinin İncelenmesi. Yayımlanmış Yüksek Lisans Tezi.

Yavuz, H. (2007). Çalışanlarda Mobbing (psikolojik şiddet) Algısını Etkileyen Faktörler: SDÜ Tıp Fakültesi Üzerine Bir Araştırma. Yayımlanmamış Yüksek Lisans Tezi, Süleyman Demirel Üniversitesi Sosyal Bilimler Enstitüsü. 